\title{
The role of insectculture in the modern paradigm of the food industry in the Republic of Tatarstan
}

\author{
Matvey S. Talan ${ }^{1, *}$, and Irina $S$. Dokuchaeva ${ }^{1}$ \\ ${ }^{1}$ Kazan National Research Technological University, Republic of Tatarstan, Russian Federation
}

\begin{abstract}
The socio-economic, biotechnological and environmental aspects of the organization of production and construction of a plant for deep processing of insectoculture in the Republic of Tatarstan are considered. Strategic analysis reveals the development of insect oculture as a key factor in improving the efficiency of food processing enterprises, organizing recycling and improving the state of the environment. The main product of the enterprise is a protein substrate, it is a well-balanced additive in mixed feed for poultry and fish farming and can become a reliable basis for import substitution in feed production. The products of vital activity of insects is a unique bio - fertilizer containing the whole complex of biologically active substances needed in crop production. The innovative technology of obtaining products of deep processing of insects is favorable not only in terms of the development of socio-economic processes in the republic, but also will give a new impetus to the development of the chemical, cosmetic and pharmaceutical industries in the Republic of Tatarstan.
\end{abstract}

\section{Introduction}

The active development of biotechnology in the leading countries of the world has turned it from an ordinary industry into the main factor determining the development of a number of vital industries, such as medicine, food industry, pharmaceuticals, alternative energy, etc. Currently, the Russian Federation lags far behind the leading countries, both in conducting basic research and in the industrial application of biotechnology.

Despite this, the Russian Federation has all the opportunities for mass use of the achievements of biotechnology and the creation of a number of industries specializing in the processing of renewable biomass, the production of food, the production of modern medicines, etc. Progress in the development of biotechnology in the Russian Federation will be achievable if it is systematic and supported by the state.

The Republic of Tatarstan has a number of important preconditions that contribute to the formation of the region biotechnology cluster on the basis of academic institutions and key sectors of the economy. However, there is currently no systematic approach to the development of the biotechnological cluster in the republic.

Industrial approbation and commercialization of the obtained technologies is constrained by a lack of funding, so the introduction and use of biotechnological research and development activities remains low. At the same time, the Republic of Tatarstan has a welldeveloped scientific infrastructure in the field of biotechnology, formed on the basis of leading research institutes and higher educational institutions of the Republic.

The search for new sources of food and feed protein is an urgent task of our time. Abroad, many authors have been dealing with the problem of waste disposal with the help of detritus insects for many years [1-7]. Insects, as a renewable raw material of animal origin, are a unique source of easily digestible proteins, fats and a whole complex of biologically active compounds [8-12]. The authors of [13-15] devoted their research to the problem of reproduction of insects on an industrial scale and in a mini-farm as a renewable raw material. In many countries, insects are widely used as feed for farm animals and poultry [16-21]. However, this technology is most widely used for aquaculture breeding: [22-251]: rainbow trout [26-291], juvenile carp [31], yellow catfish [32], tilpia [32], perch [341], white cupid [35].

Traditionally, insect food has been used in Africa, Australia, New Zealand, and China.In 2020, the EU authorities allowed the use of insects for food purposes in European countries. The fat obtained from insects is suitable for use as lubricating oils and the production of cosmetic products, chitosan and chitosan-melanin complex are used in nanopharmaceuticals, the Novovax vaccine based on moth proteins created in 2020 in the United States is ready for the last phase of clinical trials.

Previously, we studied the biotechnological potential of the house cricket Acheta domesticus [36] in comparison with other detrital insects (Hermetia Illucens and Gammarus Pulex) and studied the change in their properties during heat treatment.

Currently, there is no scientifically substantiated technology for breeding insects in the Russian

\footnotetext{
* Corresponding author: matwei.talan@yandex.ru
} 
Federation as a renewable source of protein and valuable biologically active components, and there is also no integrated processing technology that allows one to efficiently and selectively extract and store proteins and biologically active components in their native form. On the other hand, the domestic industry for the production of compound feed for fish, poultry and farm animals is experiencing an acute shortage of protein substrates for the production of compound feed.

In the Republic of Tatarstan there is a wide forage base for the reproduction of insects in the form of wastes of alcohol (alcohol stillage), brewing (brewer's grain), starch (meal) industries. However, the technology of disposal of food waste using insects has not been developed. The purpose of this study was to assess the possibility of cultivating insect biomass on a substrate from local food production waste. The objectives of the study were to study the biological characteristics of three species of insects (Hermetia Illucens, Acheta domesticus and Gammarus Pulex) in order to select the most promising insect species for cultivation in artificial conditions as an insect culture and to assess the effectiveness of bioconversion of food waste.

\section{Subjects and methods of research}

The object of the study in this work was detrital insects, Hermetia Illucens, Acheta domesticus and Gammarus Pulex, as well as food waste as substrates (brewer's grain and alcohol stillage). The choice of these species of insects as objects of study is due to the fact that they do not require specific feed, feed on organic waste, and are able to rapidly increase their biomass. The choice of brewer grains and alcohol stillage as objects of research is due to the poor knowledge of the topic and the fact that these types of organic waste are produced in the Republic of Tatarstan in the largest volumes. The Usadskiy distillery branch of JSC 'Tatspirtprom' is the largest in the Russian Federation, with a capacity of 10 thousand decaliters of rectified ethyl alcohol per day, and produces 1,300 tons of alcohol stillage per day. The same amount of waste (brewer's grains) is produced by the brewing company AB InBev Efes, which occupies about $20 \%$ of the Russian market.

The moisture content of alcohol stillage and brewer's grains was determined by drying to constant weight of the product sample at a temperature of $105^{\circ} \mathrm{C}$. Crude protein (total protein) content was determined by the Kjeldahl method. Starch was determined by enzymatic hydrolysis with subsequent determination of the formed glucose by the glucose oxidase method, cellulose - by the nitrogen-alcohol method. The mass fraction of ash was determined by burning a sample in a crucible until complete combustion of organic matter in a muffle furnace and obtaining a constant mass of the residue. The research results are shown in Table 1.

The insects were grown in a specially built insectarium. For each species of insects, special cultivators and conditions of keeping and feeding were used. The insects were grown in a specially built insectarium. For each species of insects, special cultivators and conditions of keeping and feeding were used. Gammarus crustaceans were grown in $10 \mathrm{~L}$ aquariums with tap water after settling at room temperature, the initial water $\mathrm{pH}$ 6.5-7.5.

Table 1. The main indicators of brewer grains and alcohol stillage.

\begin{tabular}{|l|c|c|}
\hline \multicolumn{1}{|c|}{ Characteristic } & Beer grains & Spirit stillage \\
\hline $\begin{array}{l}\text { Volume for 1 liter of } \\
\text { finished product }\end{array}$ & $0.25 l$ & $10 l$ \\
\hline Humidity,\% $\%$ & 6.8 & 8.2 \\
\hline Crude protein,\% & 23.4 & 26.4 \\
\hline Starch,\% $\%$ & 9.8 & 0.2 \\
\hline Cellulose,\% & 14.33 & 0.7 \\
\hline Ash content,\% & 3.2 & 1.8 \\
\hline
\end{tabular}

Feeding was performed 3 times a day in small portions to prevent water spoilage. The water was partially replaced as needed.

The cricket aquarium was covered from above with a lid with a net. The brood culture of crickets was kept separately from the larvae. As a shelter in the cages, cardboard egg molds were used, which were placed in several rows. To lay eggs, special containers filled with a substrate and moistened with water were placed in the queen cages. The larvae of the black lion fly were reared in containers filled with a moist substrate. The flies were kept in cages $60 \times 60 \times 70 \mathrm{~cm}$ in size with individual heating and temperature control within the range of $26 \pm$ $1^{\circ} \mathrm{C}$ and humidity not lower than $70 \%$.

\section{Results and discussion}

Distillery stillage is a complex polydisperse system, the solids of which are in the form of suspensions and in a dissolved state in water. Stillage contains all the nutrients of the raw materials used, with the exception of sugars and starch. The composition of vinasse contains the following amino acids: leucine, lysine, isoleucine, methionine, phenylalanine, cystine, threonine, tryptophan, valine, arginine, glutamic acid, histidine, tyrosine. The composition of vinasse contains mainly the following minerals: phosphorus, potassium, calcium, and sodium. Of the minerals in vinasse there are many potassium and phosphate salts, but little calcium and sodium salts.

The main value of stillage is in protein, the content of which in dry matter of grain stillage is on average 26$28 \%$, as well as in the presence of a number of vitamins and microelements, which makes it possible to use it as a valuable substrate for growing insect culture. Fresh stillage refers to perishable products. The permissible shelf life of it is 24 hours in the warm season, and 48 hours in the cold. Alcohol stillage is widely used in animal husbandry, however, when using fresh stillage, the main difficulty is its non-transportability due to the large amount of water and the impossibility of long-term storage.

Beer grain is formed in the process of mashing and filtration of saccharified mash and is the remainder after the separation of the liquid phase - beer wort. It is a light brown thick with a specific smell and sweetish taste of dry 
barley malt. The breweries of the $\mathrm{AB}$ InBev Efes brewing company annually produce more than 1000 thousand tons of grains with a moisture content of $70-80 \%$.

The rich chemical composition of brewer's grains makes it a promising raw material as a nutrient substrate for aquaculture cultivation.

We have found that of the three species of insects (Acheta domesticus, Hermetia Illucens and Gammarus Pulex), the most suitable for artificial breeding from a technological point of view is the species Hermetia Illucens, which is the most unpretentious, adaptive and safe insect. The full life cycle of the Black Lion fly is 75 days. Another important advantage of Hermetia Illucens is that the larval stage of the fly has the greatest ability to feed and increase the biomass. The larval stage lasts up to 20 days, depending on conditions (temperature, humidity, nutrition, illumination). At the prepupal stage, the color of the insect changes to dark brown due to the accumulation of melanin in the surface layer. In fig. 1 shows the appearance of larvae and prepupae (Fig. 2).



Fig. 1. Larvae.

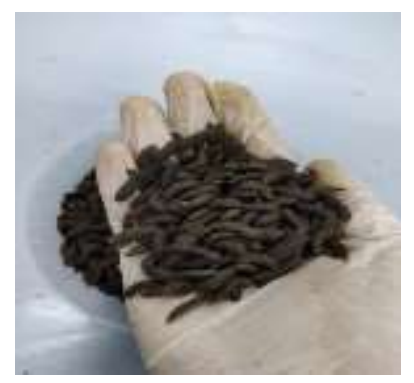

Fig. 2. Pupae.

The life cycle of Acheta domesticus crickets under artificial conditions was 47 days. Due to their high locomotor activity, crickets require significantly more growing area compared to other insects. In addition, at high breeding densities, crickets exhibit cannibalism, damaging the entire population. Gammarus, although they hold the record for protein, but their life cycle is about a year, a large water consumption and a special feeding regime are required, since when significant amounts of food debris appear, the water deteriorates, which can lead to the premature death of insects.

The economic justification of the work is based on the following factors: the price of fishmeal grows every year up to $10-20 \%$, and the volume of production decreases and depends on weather conditions and other anthropogenic factors. Development of technology and production of insect-based protein substrate will reduce the price volatility of the protein substrate, which will have a beneficial effect on the economic efficiency of agricultural production. Using organic waste from fermentation plants as a key element of the circular economy will improve the environment and significantly reduce the energy costs of food production.

\section{Conclusion}

The technology and production of insect culture in the Republic of Tatarstan is completely absent, and in the Russian Federation it is in its infancy. There are a large number of significant arguments - unpretentiousness, rapid reproducibility, environmental friendliness, availability, low cost and rich chemical composition, which determines the high biotechnological potential of insects as a source of renewable raw materials for the production of valuable components of feed and food products.

Human disgust for insects still remains a barrier to widespread cultivation of insect culture, but overcoming it seems to be secondary in comparison with the advantages that this technology provides. The implementation of these plans is promising in the field of import substitution, as it will lead to the replacement of expensive imported compound feed for feeding fish with a more affordable balanced feed containing a protein substrate from insects. Enrichment of compound feed with polyunsaturated fatty acids and obtaining competitive cosmetic products.

The socio-economic significance of this scientific work lies in the fact that the development and implementation of this technology opens up new prospects for agriculture (improving the quality of feed, reducing their cost, reducing price volatility), improving environmental management and allowing the development of new high-tech production in the pharmaceutical industry, food And the cosmetics industry.

\section{References}

1. Qing Li, Longyu Zheng, Hao Cai, E. Garza, Ziniu $\mathrm{Yu}$, Shengde Zhou. From organic waste to biodiesel: Black soldier fly. Fuel 90 1545-1548, (2011).

2. Nana, Paulin, Kimpara, Janaina Mitsue, Tiambo, Christian Keambou, Tiogue, Claudine Tekounegning, Youmbi, Jislaire, Choundong, Boniface, Fonkou, Théophile.Black soldier flies (Hermetia illucens Linnaeus) as recyclers of organic waste and possible livestock feed.Int. J. Biol. Chi. 12 (5): 2004-2015 (2018).

3. Surendra, K.C., Tomberlin, Jeffery K., van Huis, Arnold, Cammack, Jonathan A., Heckmann, LarsHenrik L., Khanal, Samir Kumar. Rethinking organic wastes bioconversion: Evaluating the potential of the black soldier fly (Hermetia illucens (L.)) (Diptera: Stratiomyidae). Waste Management, 117, 58-80, (2020).

4. Pamintuan, Kristopher Ray S., Agustin, Hanika Angel T., Deocareza, Ericka D. Growth and 
Nutritional Performance of Black Soldier Fly ( Hermetia illucens ) Larvae Reared in Fermented Rice Straw and Duck Manure Journal: IOP Conf. Ser.: Earth Environ. Sci. 505 012030. (2020).

5. Fadhillah, N, Bagastyo, A. Y. Utilization of Hermetia illucens Larvae as A Bioconversion Agent to Reduce Organic Waste. IOP Conf. Ser.: Earth Environ. Sci. 506 012005. (2020).

6. Gligorescu, Anton, Fischer, Christian Holst, Larsen, Peter Foged, NÃ,rgaard, Jan VÃ'rum, Heckman, Lars-Henrik Lau. Production and Optimization of Hermetia illucens (L.) Larvae Reared on Food Waste and Utilized as Feed Ingredient.Sustainability, 12, 9864 (2020).

7. Kinasih, I, Suryani, Y, Paujiah, E, Ulfa, RA, Afiyati, S, Adawiyah, YR, Putra, RE. Performance of Black Soldier Fly, Hermetia illucens, Larvae during valorization of organic wastes with changing quality. IOP Conf. Ser.: Earth Environ. Sci. 593 . (2020).

8. Müller, A., Wolf, D., \& Gutzeit, H. O. The black soldier fly, Hermetia illucens-a promising source for sustainable production of proteins, lipids and bioactive substances. Zeitschrift für Naturforschung C, 72(9-10), 351-363, (2017).

9. van der Fels-Klerx, H. J., Meijer, N., Nijkamp, M. M., Schmitt, E., \& van Loon, J. J. A. Chemical food safety of using former foodstuffs for rearing black soldier fly larvae (Hermetia illucens) for feed and food use. Journal of Insects as Food and Feed, 6(5), 475-488, (2020).

10. Marusich, E., Mohamed, H., Afanasev, Y., \& Leonov, S. Fatty Acids from Hermetia illucens Larvae Fat Inhibit the Proliferation and Growth of Actual Phytopathogens. Microorganisms, 8(9), 1423, (2020).

11. Barragan-Fonseca, K. B., Gort, G., Dicke, M., \& van Loon, J. J. A. Nutritional plasticity of the black soldier fly (Hermetia illucens) in response to artificial diets varying in protein and carbohydrate concentrations. Journal of Insects as Food and Feed, 1-12, (2020).

12. Khayrova, A., Lopatin, S., \& Varlamov, V. Obtaining Chitin/Chitosan-Melanin Complexes from Black Soldier Fly Hermetia Illucens. In IOP Conference Series: Materials Science and Engineering (Vol. 809, No. 1, p. 012020). IOP Publishing, (2020).

13. Gligorescu, A., Toft, S., Hauggaard-Nielsen, H., Axelsen, J. A., \& Nielsen, S. A. Development, metabolism and nutrient composition of black soldier fly larvae (Hermetia illucens; Diptera: Stratiomyidae) in relation to temperature and diet. Journal of Insects as Food and Feed, 4(2), 123-133, (2018).

14. Liu, Z., Najar-Rodriguez, A. J., Minor, M. A., Hedderley, D. I., \& Morel, P. C. Mating success of the black soldier fly, Hermetia illucens (Diptera: Stratiomyidae), under four artificial light sources.
Journal of Photochemistry and Photobiology B: Biology, 205, 111815, (2020).

15. Scala, A., Cammack, J. A., Salvia, R., Scieuzo, C., Franco, A., Bufo, S. A., \& Falabella, P. Rearing substrate impacts growth and macronutrient composition of Hermetia illucens (L.)(Diptera: Stratiomyidae) larvae produced at an industrial scale. Scientific reports, 10(1), 1-8, (2020).

16. Barragan-Fonseca, K. B., Dicke, M., \& van Loon, J. J. Nutritional value of the black soldier fly (Hermetia illucens L.) and its suitability as animal feed-a review. Journal of Insects as Food and Feed, 3(2), 105-120. (2017).

17. Ruhnke, I., Normant, C., Campbell, D. L., Iqbal, Z., Lee, C., Hinch, G. N., \& Roberts, J. Impact of onrange choice feeding with black soldier fly larvae (Hermetia illucens) on flock performance, egg quality, and range use of free-range laying hens. Animal Nutrition, 4(4), 452-460, (2018).

18. Pieterse, E., Erasmus, S. W., Uushona, T., \& Hoffman, L. C. Black soldier fly (Hermetia illucens) pre-pupae meal as a dietary protein source for broiler production ensures a tasty chicken with standard meat quality for every pot. Journal of the Science of Food and Agriculture, 99(2), 893-903, (2019).

19. Cullere, M., Woods, M. J., van Emmenes, L., Pieterse, E., Hoffman, L. C., \& Dalle Zotte, A. Hermetia illucens larvae reared on different substrates in broiler quail diets: effect on physicochemical and sensory quality of the quail meat. Animals, 9(8), 525, (2019).

20. El-Hack, A., Mohamed, E., Shafi, M. E., Alghamdi, W. Y., Abdelnour, S. A., Shehata, A. M., ... \& Ragni, M. Black Soldier Fly (Hermetia illucens) Meal as a Promising Feed Ingredient for Poultry: A Comprehensive Review. Agriculture, 10(8), 339, (2020)

21. Oluokun, J. A. Upgrading the nutritive value of fullfat soyabeans meal for broiler production with either fishmeal or black soldier fly larvae meal (Hermetia illucens). Nigerian Journal of Animal Science, 3(2), (2020).

22. Rumpold, B. A., Speckmann, H., Schlüter, O., Kloas, W., \& Prochnow, A. Potentials of a biogenic residue-based production of Hermetia illucens as fish meal replacement in aquafeed for Oncorhynchus mykiss in Germany. Journal of Insects as Food and Feed, 4(1), 5-18, (2018).

23. Yusuf, M., Purwanti, S., \& Mujnisa, A. Substitutions of fish meal with larvae meal black soldier fly (Hermetia illucens) on the performance of female quail. In IOP Conference Series: Earth and Environmental Science (Vol. 492, No. 1, p. 012013). IOP Publishing, (2020).

24. Guerreiro, I., Serra, C. R., Coutinho, F., Couto, A., Castro, C., Rangel, F., ... \& Enes, P. Digestive enzyme activity and nutrient digestibility in meagre (Argyrosomus regius) fed increasing levels of black 
soldier fly meal (Hermetia illucens). Aquaculture Nutrition, 27(1), 142-152, (2021).

25. Moutinho, S., Pedrosa, R., Magalhães, R., OlivaTeles, A., Parisi, G., \& Peres, H. Black soldier fly (Hermetia illucens) pre-pupae larvae meal in diets for European seabass (Dicentrarchus labrax) juveniles: Effects on liver oxidative status and fillet quality traits during shelf-life. Aquaculture, 533, 736080, (2021).

26. Dumas, A., Raggi, T., Barkhouse, J., Lewis, E., \& Weltzien, E. The oil fraction and partially defatted meal of black soldier fly larvae (Hermetia illucens) affect differently growth performance, feed efficiency, nutrient deposition, blood glucose and lipid digestibility of rainbow trout (Oncorhynchus mykiss). Aquaculture, 492, 24-34, (2018).

27. Bruni, L., Pastorelli, R., Viti, C., Gasco, L., \& Parisi, G. Characterisation of the intestinal microbial communities of rainbow trout (Oncorhynchus mykiss) fed with Hermetia illucens (black soldier fly) partially defatted larva meal as partial dietary protein source. Aquaculture, 487, 56-63, (2018).

28. Renna, M., Schiavone, A., Gai, F., Dabbou, S., Lussiana, C., Malfatto, V., \& Gasco, L. Evaluation of the suitability of a partially defatted black soldier fly (Hermetia illucens L.) larvae meal as ingredient for rainbow trout (Oncorhynchus mykiss Walbaum) diets. Journal of animal science and biotechnology, 8(1), 1-13, (2017).

29. Kumar, V., Fawole, F. J., Romano, N., Hossain, M. S., Labh, S. N., Overturf, K., \& Small, B. C. Insect (black soldier fly, Hermetia illucens) meal supplementation prevents the soybean meal-induced intestinal enteritis in rainbow trout and health benefits of using insect oil. Fish \& Shellfish Immunology, 109, 116-124, (2021).

30. Ushakova, N. A., Udalova, Z. V., Zinovieva, S. V., \& Garmash, N. Y. Development of effective substrates for growing Hermetia illucens larvae with a high protein content and assessment of the effect of the obtained zoocompost on phytonematode. In IOP Conference Series: Earth and Environmental Science (Vol. 548, No. 8, p. 082087). IOP Publishing, (2020).

31. Li, S., Ji, H., Zhang, B., Tian, J., Zhou, J., \& Yu, H. Influence of black soldier fly (Hermetia illucens) larvae oil on growth performance, body composition, tissue fatty acid composition and lipid deposition in juvenile Jian carp (Cyprinus carpio var. Jian). Aquaculture, 465, 43-52, (2016).

32. Xiao, X., Jin, P., Zheng, L., Cai, M., Yu, Z., Yu, J., \& Zhang, J. Effects of black soldier fly (Hermetia illucens) larvae meal protein as a fishmeal replacement on the growth and immune index of yellow catfish (Pelteobagrus fulvidraco). Aquaculture research, 49(4), 1569-1577, (2018).

33. Devic, E., Leschen, W., Murray, F., \& Little, D. C. Growth performance, feed utilization and body composition of advanced nursing Nile tilapia
(Oreochromis niloticus) fed diets containing Black Soldier Fly (Hermetia illucens) larvae meal. Aquaculture nutrition, 24(1), 416-423, (2018).

34. Stejskal, V., Tran, H. Q., Prokesova, M., Gebauer, T., Giang, P. T., Gai, F., \& Gasco, L. Partially Defatted Hermetia illucens Larva Meal in Diet of Eurasian Perch (Perca fluviatilis) Juveniles. Animals, 10(10), 1876, (2020).

35. Lu, R., Chen, Y., Yu, W., Lin, M., Yang, G., Qin, C., ... \& Nie, G. Defatted black soldier fly (Hermetia illucens) larvae meal can replace soybean meal in juvenile grass carp (Ctenopharyngodon idellus) diets. Aquaculture Reports, 18, 100520, (2020).

36. Talan, M. S., Lapin, A. A., \& Dokuchaeva, I. S. (2019, August). Biotechnological potential of the straight-wing species Acheta domesticus as raw material for the production of feed for aquaculture. In IOP Conference Series: Earth and Environmental Science (Vol. 315, No. 7, p. 072035). IOP Publishing. 